\title{
Realising benefits in primary healthcare infrastructures
}

\begin{abstract}
Purpose: This paper focuses upon the requirements to manage change, tangible and intangible benefits in a joint approach to deliver outputs on time, to quality and cost without failing to realise the benefits of the change. The aim of the paper is to demonstrate the need for benefits driven programme/project management as well as the importance of identifying the stakeholders' level of involvement and contribution throughout the process, and manage their expectations.
\end{abstract}

Design/methodology/approach: The methodology used is based on an action research approach, combining findings from a literature review and case studies within UK's primary healthcare sector.

Findings: Findings demonstrate development of a Benefits Realisation (BeReal) approach in healthcare through looking at case studies taking place within UK's primary and acute healthcare sector

Research limitations/implications: The framework development is based upon theoretical evidence and further research is needed to test and validate its robustness.

Originality/value: The application of Benefits Realisation and Management in developing and delivering primary healthcare facilities.

Keywords: Benefits management, Benefits realisation, healthcare infrastructures, process and LIFT

Paper type Conceptual paper

\section{Introduction}

Major capital investment programmes and projects, including those within the public sector, traditionally determine their level of success against cost, quality and time of delivery, and not in relation to the benefits or impact that they have delivered. Benefits Realisation is emerging as one of the methods to assist organisations to manage the whole life cycle of programmes and projects (Glynne, 2007).

Reiss et al (2006) describe that a common characteristic of many unsuccessful programmes is the vagueness with which the expected benefits are defined. Without clearly defined benefits, it is difficult to maintain focus when subsequent problems occur. The costs of undertaking programmes are real and immediate, while the benefits frequently only occur after the programme is completed and implemented. Furthermore, the people responsible for actually delivering the benefits are often different from those responsible for directing and managing the programme itself. This is even more evident in the case of Healthcare Capital investment programmes due to the huge diversity of the stakeholders involved and the different levels of activity and decision making that such programmes go through prior to their completion. As a result, it is only when the expected benefits are fully defined, understood and agreed, at the start of the program, that the investors and policy makers can be confident that the investment is likely to be successful. This understanding must be supported by mechanisms to measure the benefits and with procedures for monitoring, reporting and, most importantly, responding to their achievement or non-achievement.

The Health and Care Infrastructure Research and Innovation Centre (HaCIRIC) based in the UK is undertaking a research project in Benefits Realisation to develop a framework that will meet the demands above, promoting continuous improvement and organisational learning. This paper will present the work that HaCIRIC has been undertaking to develop this framework through case studies in an action research mode within the healthcare settings.

A literature review identified a limited amount of research papers on the theory of benefits management and realisation. The majority of the literature is from benefits 
realisation and management approaches of the implementation of IT/IS (spell out please) systems.

HaCIRIC's research project and in particular this paper has a generic focus on how benefits should be identified at policy level, deployed within a programme's or a project's business case and subsequently drive the programme or project to ensure end-user satisfaction. This paper aims to introduce the importance of applying benefit realisation throughout the lifecycle of a healthcare infrastructure programme, to ensure that what the programme set out to do at the initial stages is managed and achieved.

\section{Research Method}

The overarching research philosophy adopted for this project is an actor based research philosophy (Berger \& Luckmann 1966) as used in the development of the Generic Design and Construction Process Protocol (Kagioglou et al 2000). It consists of the preunderstanding - understanding hermeneutic spiral (Odman 1985). The research has adopted an action research approach, which is interactive in nature (Susman and Evered 1978) and provides the platform where HaCIRIC's research team and the industrial partners can agree on the issues, monitor the present situation, analyse data, identify process improvements and subsequently reflect and evaluate upon impact (see Fig. 1). This took place in the form of advisory group meetings, steering group meetings and project team meetings. The different level of meetings allowed different perspectives to be captured.

\section{Fig. 1 Action Research Process}

The information for the project is gathered through multiple case studies. Multiple case studies allows findings to be compared between the different cases, increasing the robustness of the research (Herriott and Firestone, 1983). This multi-site approach enables the transferability of the research findings to be measured at the same time as capturing wider user perspectives (Yin, 2003; Kagioglou et al, 2000).

The BeReal model introduced later in this paper is being informed and tested through case studies at different stages of the lifecycle of a healthcare programme (Yates et al 2008). It would have been difficult to undertake one case study to test and validate the whole framework given time constraints, as the whole lifecycle of such projects spans from 20 to 30 years. The decision was made to undertake case study snapshots of the development of a healthcare infrastructure programme aiming to inform the framework in phases and by using different procurement routes within the healthcare sector. Following that approach five case studies are currently undertaken. The portfolio of case studies is as follows;

I. At policy setting phase there is close collaboration with Community health Partnerships (CHP).

II. At programme development level the case study involves identification of benefits within the Cumbria Community Ventures programme lead by Cumbria Primary Care Trust.

III. At business case development level there are two case studies one with Stockport PCT looking at benefits identification and benefits mapping for the local Community Hospital and one with Brighton and Sussex NHS trust testing the same phase of the framework for the development of a new Tertiary care, Trauma and Teaching (3Ts) hospital.

IV. At post occupancy evaluation (POE) the case study is investigating the flowdown of benefits and the validation of the BeReal benefits review techniques at three MaST LIFT first wave schemes that have been operational between 18-24 months 
A variety of quantitative and qualitative methods were adopted to collect data, including questionnaires, semi-structured interviews and interactive workshops. These are used to develop, implement and evaluate the Benefits Realisation Framework (BeReal) from multiple perspectives. Questionnaire data was analysed using a Statistical Package for the Social Sciences (SPSS) for closed questions. Non-numerical, Unstructured Data Indexing, Searching and Theorising (NUD*ST) was adopted for the analysis of open questions (Harris et al, 2008).

\section{Benefits Terminology}

Although the word 'benefit' is used widely in everyday life it is very poorly defined. It can simply be introduced as 'a measurable improvement'. A benefit 'is an outcome whose nature and value are considered advantageous by an organization”(OGC, 2007b, Thorp, 1998, Ward et al., 1995). Bradley (2006) defines it as an outcome of change which is perceived as positive by a stakeholder and, following the same thought, Ward and Daniel (2006) define it as 'an advantage on a behalf of a particular stakeholder or group of stakeholders' The important point in the two later definitions is that benefits are owned by individuals or groups who want to obtain value from an investment (Glynne, 2007).

Outcomes are not always expected and positive, the may also be negative and unexpected (Ward et al. 2004); with the combination of this two factors potentially leading to disbenefits (Nogeste 2005). The term 'disbenefit' is a key element of many benefits realisation/ management approaches and it was first introduced in the context of an IT/IS implementation. It relates to the adverse effect that a new IT programme could have in the organisations information flow stability. 'Disbenefit', in more generic terms, is defined as something disadvantageous or objectionable (Merriam-Webster, 2005); something that makes a situation disadvantageous or unfavourable (Encarta $\left.{ }^{\circledR}, 2005\right)$; and in financial terms as the undesirable effect of an investment (Bannister et al., 2001). An organisation or investors need to agree that negative outcomes or disbenefits are the 'price worth paying to obtain positive benefits' (Ward et al 2004). The incorporation of disbenefits would introduce greater balance into investment evaluation techniques which currently focus upon benefits and ignore disbenefits (Fox, 2008).

\section{Benefits Classification}

Classification of benefits is attempted by many authors according to a variety of criteria. This helps to increase the understanding of the nature of benefits, and will assist analysis and communication (Bradley 2006). Table 1 shows some type of benefits as described in the literature, being the most common distinction that between tangible and intangible benefits. 
Table 1: Benefits types

(Ward and Daniel (2006) Farbey et al 1999, Bradley (2006) Ward (1996) Ashurst and Doherty (2003), Mantzana and Themistocleous (2004), Bartlett (2006), Lin and Pervan (2001) Nogeste and Walker (2005) and Reiss et al (2006))

\begin{tabular}{|l|l|}
\hline Benefit Types & Description \\
\hline Tangible (hard /direct) & $\begin{array}{l}\text { Judged objectively, uses quantitative measures which } \\
\text { are often but not always financial. }\end{array}$ \\
\hline Intangible ( soft /indirect) & $\begin{array}{l}\text { Judged subjectively and tend to employ qualitative } \\
\text { measures, often difficult to measure and almost } \\
\text { always difficult to convert to monetary values. }\end{array}$ \\
\hline $\begin{array}{l}\text { By Organisational or } \\
\text { business impact }\end{array}$ & \begin{tabular}{l} 
These come in 5 different business streams: \\
- Strategic; \\
- Management; \\
- Operational; \\
- Functional; \\
- Support. \\
\hline orientated
\end{tabular} \\
$\begin{array}{l}\text { Classification of benefits and disbenefits according to } \\
\text { the stakeholder (groups) who will feel or experience } \\
\text { their impact. } \\
\text { In an investment, project or programme the } \\
\text { actors/stakeholders can be classified in four main } \\
\text { categories: } \\
\text { - Providers; } \\
\text { - Acceptors; } \\
\text { - Supporters; } \\
\text { - Controllers, both human or organisational; } \\
\text { - }\end{array}$ \\
\hline Unplanned/Emergent \\
$\begin{array}{l}\text { These are often a consequence of a change } \\
\text { implemented or another benefit gained. They are } \\
\text { documented in business cases as a result of a change } \\
\text { or an investment. }\end{array}$ \\
\hline
\end{tabular}

\section{Benefits Management and Realisation}

Farbey et al (1999) define benefit realisation management as "the process that realises the benefits that are achieved and manages the unexpected ones”, and Bradley (2006) defines it as "the process of organising and managing, so that potential benefits arising from investment in change, are actually achieved”. Reiss et al (2006) define benefits management as "the process for the optimisation or maximisation of benefits from organisation change programmes”.

According to Lin and Pervan (2001), benefits management is the procedural approach of how to manage the benefits evaluation to realise the benefits of capital investments. Within a programme management setting (OGC, 2007b) benefits management complements and overlaps investment appraisal in the business case. While investment appraisal provides the justification for the investment, benefits management allows the organisation to plan for and achieve the benefits. 
Since 1995 there have been several 'Benefits Management/Realisation’ approaches developed, table 2 gives details of these.

Table 2: Benefits Realisation and Management Approaches \& Models (Sapountzis, Harris and Kagioglou 2008a)

\begin{tabular}{|c|c|}
\hline Approach/Model & Details \\
\hline $\begin{array}{lr}\text { Active } & \text { Benefits } \\
\text { Management (Leyton, 1995) }\end{array}$ & $\begin{array}{l}\text { Sets the benefits management activity in the } \\
\text { context of business change. Identifies continuous } \\
\text { flow between change and benefits }\end{array}$ \\
\hline $\begin{array}{l}\text { The Cranfield } \quad \begin{array}{c}\text { process } \\
\text { model of }\end{array} \text { Benefits } \\
\text { Management (Ward et al., } \\
\text { 1996) }\end{array}$ & $\begin{array}{l}\text { Key feature of this model is benefits monitoring. } \\
\text { This compares project results with the benefits } \\
\text { realisation plan during the project and assesses if } \\
\text { any internal or external changes have occurred } \\
\text { that will affect the delivery of planned benefits. } \\
\text { Potential benefits are identified, a plan is devised } \\
\text { for their realisation, the plan is executed, the } \\
\text { results reviewed and evaluated and feedback } \\
\text { occurs. }\end{array}$ \\
\hline $\begin{array}{l}\text { The Benefits Realisation } \\
\text { Approach (BRA) (Thorp, } \\
\text { 1998) }\end{array}$ & $\begin{array}{l}\text { Is based on two cornerstones: } \\
\text { 1. The shift from stand alone project management } \\
\text { to: Business Programme Management, } \\
\text { Disciplined Portfolio Management, Full cycle } \\
\text { governance. } \\
2 \text { The three necessary conditions for the } \\
\text { successful implementation of the BRA are: (a) } \\
\text { accountability of activists; (b) relevant measure; } \\
\text { and (c) proactive management of change to give } \\
\text { people ownership stakes in programs. }\end{array}$ \\
\hline $\begin{array}{l}\text { Active Benefit Realisation } \\
\text { (ABR) (Remenyi and } \\
\text { Sherwood-Smith, 1998) }\end{array}$ & $\begin{array}{l}\text { A process for managing information systems' } \\
\text { development through a continuous evaluation } \\
\text { approach. ABR requires a direct and continuous } \\
\text { focus on business benefits realisation and is } \\
\text { based on a contingency philosophy. }\end{array}$ \\
\hline $\begin{array}{l}\text { Towards best practice to } \\
\text { Benefits } \\
\text { (Ashurst and Donagement } \\
\text { 2003) }\end{array}$ & $\begin{array}{l}\text { In this approach benefits realisation is a } \\
\text { continuous process through an evolving } \\
\text { organisational context. But it does not take into } \\
\text { account influences that external factors may have } \\
\text { onto a project" }\end{array}$ \\
\hline $\begin{array}{l}\text { Managing Successful } \\
\text { programmes (MSP) (OGC } \\
\text { 2007) }\end{array}$ & $\begin{array}{l}\text { MSP represents the UK Government's view on } \\
\text { the programme management principles and } \\
\text { techniques. MSP identifies benefits management } \\
\text { as 'a core activity and a continuous 'thread' } \\
\text { throughout the programme" (OGC, 2007), and } \\
\text { fundamental to the realisation of benefits from } \\
\text { new capabilities delivered by projects within the } \\
\text { programme. Emphasis is placed on identification, } \\
\text { quantification, assignment of owners and } \\
\text { tracking, it has been heavily influenced by } \\
\text { Cranfield's Benefits Management model and } \\
\text { Bradley's Benefits Realisation Management }\end{array}$ \\
\hline
\end{tabular}




\begin{tabular}{|c|c|}
\hline & 2006. \\
\hline The Gateway ${ }^{\mathrm{tm}}$ Process & $\begin{array}{l}\text { The Gateway Review Process indicates, at a high } \\
\text { level, dependencies between a typical Benefits } \\
\text { Management process and the steps for managing } \\
\text { a major delivery programme. It also maps the } \\
\text { main benefits management steps onto the } \\
\text { standard delivery stages described in both MSP } \\
\text { and OGC Gateway Reviews, but the approach } \\
\text { can be used for any type of more specialised } \\
\text { change initiative. This process contains } \\
\text { identification of potential benefits their planning, } \\
\text { modelling and tracking, the assignment of } \\
\text { responsibilities and authorities and their actual } \\
\text { realisation. }\end{array}$ \\
\hline $\begin{array}{l}\text { Benefits Management in the } \\
\text { Handbook of Programme } \\
\text { Management (Reiss et al } \\
\text { 2006) }\end{array}$ & $\begin{array}{l}\text { This approach focuses the benefits management } \\
\text { model in the delivery of benefits by projects } \\
\text { (Nogeste and Walker, 2005). Reiss (2006) define } \\
\text { the scope of benefits management as "the } \\
\text { management and monitoring of benefits during } \\
\text { and after execution phase' and depicts the "value } \\
\text { path" relationship between benefits and projects } \\
\text { as a Hierarchical Benefits structure (Nogeste and } \\
\text { Walker, 2005) }\end{array}$ \\
\hline
\end{tabular}

It is common for some benefits not to be realised until many years beyond implementation. Often benefits are never realised or mismanaged because benefits management ends with closure of a project or programme (Glynne, 2007). Parr and Williams (2007) acknowledge that ambiguity can exist between project /programme and business operations responsibility: 'the need for clearly defined responsibilities and assignment of these to roles and individuals is heightened within benefits management because of the potential ambiguity between tasks for the delivery team, and tasks for the operational business', as argued by Cooke-Davies (2002). It is common mistake for project's and programme's managers to own the benefits and not involve those directly tasked with managing change within the business organisation (Glynne, 2007). For a programme or project to be successful, there must be an agreed governance model that ensures ownership and accountability until all benefits have been formally reviewed and measured (Bradley, 2006, Glynne, 2007, Ward and Daniel, 2006).

The concept of managing benefits in order to ensure their delivery is usually new within a sector or organisation. The various stakeholders will need to understand how benefits are to be identified, modelled and subsequently delivered (Reiss et al., 2006). It would be risky to assume that all stakeholders will understand the implications of benefits identification and planning. Kagioglou et al (2000) highlights that project success relies on the right people having the right information at the right time, supporting the active involvement of all participants, especially in the early phase of a project. This may subsequently help to foster a team environment and encourage appropriate communication and decision making. Achieving successful change is much easier if all stakeholders are committed and the earlier this commitment is accomplished, the smother the path to a successful outcome (Bradley, 2006).

The understanding that benefits do not just happened by delivering projects must be supported with mechanisms to measure the benefits; and with procedures for monitoring, 
reporting and responding to their achievement or non-achievement (Reiss et al., 2006). Payne (2007) supports that view and adds that there should also be two more critical elements in a balanced benefits management environment i.e. leadership and people/organisation.

\section{The need for a benefits realisation process for primary healthcare infrastructures}

Benefits Realisation is especially important within a healthcare setting as the process along with the formal appraisal, evaluation and management schemes as it 'helps to ensure a clear sign posting of who is responsible for the delivery of those benefits' (NHS No delays website, 2007). Within such large and complex environment this is very important in ensuring it runs efficiently and effectively (Sapountzis et al, 2008b).

Continuous changes in the NHS structure, governance, roles etc have had and will continue to have a huge impact on the ability to evaluate services. Farbey et al (1999) explain that the shift in responsibility and power between workers due to organisational structure changes, has led to confusion over priorities.

In 2001 Partnerships for Health (PfH), now known as Community Health Partnerships (CHP) introduced Local Improvement Finance Trust (LIFT). LIFT is a new procurement route for primary care services (Fig. 2.). This Public Private Partnership (PPP) is now fully owned by the Department of Health as an arms length organisation. The main challenge was to invest in premises that meet the requirements and are appropriate for current and future integrated Primary Care delivery (DoH Website). Like the Private Finance Initiative (PFI), LIFT is a way of accessing private funds for public projects LIFT varies from area to area in terms of what it delivers to that community. This is because it is specific to that local community and the population's requirements.

\section{Fig. 2 LIFT Structure (NAO 2005)}

HaCIRIC's Benefits Realisation Process in the context of primary healthcare aims to provide a framework to evaluate to what extent the benefits listed below have been realised by the introduction of LIFT:

- Alignment with the Government's regeneration policy by making healthcare more accessible and bringing it to deprived areas of the country (House of Commons, 2006).

- Provides the community with facilities e.g. leisure centre that may not have been possible without the scheme.

- 'In addition a LIFT company will be encouraged to identify other potential occupants or users of facilities or other commercial opportunities that may help make a development financially viable or enhance profitability as well as offering flexibility to respond to changing requirements' (Cartlidge, 2006).

- Sustainability for the delivery of healthcare (DoH website)

- 'Investment in modern integrated primary care services in areas where patients most need it' (DoH website).

- The services that will be provided will be using a common approach developed by Partnerships for Health. This will result in a more equal delivery of health across the England and Wales.

- Co-location of many services means the integration of health and social care facilities, resulting in a much more accessible healthcare system.

- Through co-location of a range of healthcare services secondary care can occur within primary care facilities, "allowing faster and more convenient referrals, where the relevant specialists hold clinics in LIFT premises” (House of Commons, 2006). 
- Buildings that are fully functional and able to delver to the local community the care in terms of health and social that is needed over a period of 20 years (House of Commons, 2006).

With such a large investment into LIFT and so many benefits expected there is a need to evaluate how successful LIFT has actually been. However as stated in the House of Commons report (2006) "It will be many years before the expected benefits of delivering services to local communities through LIFT can be realised." Other problems in evaluating identified in the report include (House of Commons Report, DATE):

- "Comparing the value for money of LIFT with other procurement routes is not straightforward because the LIFT framework is designed to offer tenants more and better services than obtainable under a standard commercial lease. LIFT also delivers a broader and more complex range of services to patients than typical primary care premises.

- Moreover, the contribution of the LIFT initiative to better health outcomes or to the wider community, for example in terms of meeting a local regeneration agenda, is hard to quantify.”

\section{The BeReal Model and its main stages}

As a result of the initial literature review and the identification of the primary healthcare sector's need for benefits realisation, through interviews and workshops with healthcare management professionals and practitioners a Benefits realisation (BeReal) framework is introduced. The framework aims to address these needs and assist the LIFT community in identifying, managing and realising the benefits that it has been created to deliver.

The BeReal framework is based on the following issues:

- Although the need of benefits realisation has coincided with the increasing use and complexity of IT systems it is now an emergent and vital element for 'best practice' programme or project management in any major capital investment

- The need for classification of benefits in terms of value, organisational impact (internal and external), planned and unplanned

- The importance to understand the differentiation between tangible and intangible benefits and how those may be managed and realised.

- The importance to define clear roles and responsibilities for successful benefits management and the necessity of robust methods of governance.

- Linkages between continuous improvement (CI) and benefits management and how essential is the measurement, monitoring and reviewing of benefits to maintain a CI momentum either within an existing programme/ project or when planning for new ones.

- The relationship between value and benefits and existing evaluation stages and techniques.

- the connections between benefits management and other management disciplines as the interdependence of BM and other disciplines is not fully reflected in the literature researched.

- The performance management as route for better management and accountability that provides information required for process control, enabling the establishment of real but challenging targets that could be translated into benefits. 
- Value generation and elimination of wasteful activities in programme development, implementation and delivery.

- Embedment or integration of benefits realisation and business case to act as one powerful document that will be flexible to changes.

- Clear links between benefits realisation plan and outcomes

- Knowledge sharing \& continuity.

- Understanding of the 'benefits' and 'value' of activities by all that plan, deliver and receive a project

The BeReal framework breaks down the benefits management and realisation activities into four main phases. The phases are designed and distinguished as such so an alignment with current traditional investment and development processes can be achieved. Although its phase is represented as an individual set of activities with clear deliverables the thought behind it is to provide flexibility and a' soft gate' approach between stages (Kagioglou et al, 1999), to ease its adaptation and implementation when aligned with an organisation's own decision making process.

The four main phases have been identified as:

\section{Phase 1 - Benefits Management Strategy \& Benefits Realisation case}

This first phase is concerned with identifying desired top benefits and developing a benefits management strategy in order to share and communicate these to the wider stakeholder group. The benefits management strategy forms the base of the development of a benefits realisation case of support should form the nucleus of the project's business case.

Phase 2 - Benefits profile \& benefits mapping

Project group meetings and benefits mapping workshops with the appropriate group of stakeholders are critical for the success of this phase. The benefits mapping and profiling form the basis of an ongoing benefits realisation plan.

Phase 3 - Benefits realisation plan

This phase focuses on the execution of a benefits realisation plan as that is developed and formulated in the first two phases it consists of measuring and tracking the benefits previously identified and incorporating emerging ones, through data collection and measurement.

Phase 4 - Benefits evaluation and review

This phase consist of the evaluation of the benefits as these have been identified or emerged through the previous phases.

Most of the approaches reviewed in the literature tend to focus on the continuous improvement cycle of Plan -Do - Check-Act (PDCA). The same logic is adopted by the BeReal framework adding to the PDCA cycle the Evaluation entity and extending in to an EPDCA cycle.

The BeReal framework is designed to be flexible and adaptable onto any key decision making process. As the main sector of the application of the frame work is the healthcare sector figure 3 illustrates how the framework can be aligned with the predominant investment, development and decision making processes currently used by the healthcare 
sector, including OGC's Gateway process, the Capital investment manual by the Department of Health, a traditional PFI development process and the LIFT project development process. 2008)

Fig. 3 Alignment of BeReal Framework with other processes (Sapountzis et al,

\section{Summary and concluding remarks}

It is evident from the literature that major capital investment programmes and projects are measured on their success in relation to cost, quality and time of delivery, and not in relation to the benefits or impact that they have delivered. Although benefits realisation is emerging as one of the methods to assist organisations to manage the whole life cycle of programmes and projects, there appears to be no evidence in the literature of the successful implementation of any of the methods available. The framework presented in this paper describes the benefits realisation process into four main phases: Benefits Strategy, Benefits Profile, Benefits realisation Plan and Benefits Evaluation \& review.

The BeReal framework has been developed and is being further informed and validated through case studies in a context of the health and social care services infrastructure delivery. . The framework has been developed through extensive literature review, interactive workshops with key stakeholders from a wide spectrum of disciplines, such as Healthcare, Local Councils, Government agencies, as well as the design and construction industry. Its effective implementation will depend upon the simplicity of the framework, the organisations readiness to use it and an effective change management culture. Further research can demonstrate the generic applicability of the framework to managing programmes and projects in arenas other than healthcare capital investment.

\section{References}

Ashurst, C. \& Doherty, N. F. (2003) "Towards the formulation of 'a best practice' framework for benefits realisation in IT projects”, Electronic Journal of Information Systems Evaluation, 6, 1-10.

Bannister, F., McCabe, P. \& Remenyi, D. (2001) "How much did we really pay for that? The awkward problem of information technology costs", The Electronic Journal of Information Systems Evaluation, Vol. 5, 1-11.

Bartlett, J. (2006), "Managing programmes of business change" (4th Edition), Project Manager Today, Hampshire, UK

Berger, P.L. and Luckemann, T. (1966), The Social Construction of Reality, Doubleday, Garden City, NY

Bradley, G. (2006) Benefit Realisation Management - A Practical guide to achieving benefits through change, Hampshire, UK, Gower.

Cartlidge, D. (2006) Public Private Partnerships in Construction, Taylor \& Francis

CCTA (1999) Managing Successful Programmes, The Stationery Office.

Cooke-Davies, T. (2002) “The 'real' success factors on projects”, International Journal of Project Management, Vol. 20 pp. 185-190.

Department of Health website, http://www.dh.gov.uk/en/index.htm (accessed 03 August 2008)

ENCARTA ${ }^{\circledR}$ (2005) http://encarta.msn.com/dictionary/disbenefit.html. Buffalo, NY, Encarta ${ }^{\circledR}$ Dictionary. Microsoft Encarta ${ }^{\circledR}$ (accessed May2008) 
Farbey, B., Land, F. \& Targett, D. (1999) "The moving staircase - problems of appraisal and evaluation in a turbulent environment”, Information Technology and People Journal, Vol. 12, pp. 238-252.

Glynne, P. (2007) "Benefits management-changing the focus of delivery", Association for Progress Management Yearbook 2006/07, pp. 45-49.

Harris, K. A, Sapountzis, S., and Kagioglou, M. (2008) "The methodological development of a Benefits Realisation Management Process (BRMP) in the case of Manchester, Salford and Trafford (MaST) Local Improvement Finance Trust (LIFT)”, 8th BuHu International Postgraduate Research Conference, June 26 -27 Prague, Czech Republic

Herriott, R. E. and Firestone, W. A. (1983) Mutisite qualitative policy research: Optimizing description and generalizability, Educational Researcher, Vol. 12, 14-19

House of Commons (2006) NHS Local Improvement Finance Trusts: forty Seventh Report of Session 2005-2006, The Stationary Office, London

Kagioglou, M., Cooper, R., Aouad, G. and Sexton, M. (2000) "Rethinking Construction: the Generic Design and Construction Process Protocol”, Engineering, Construction and Architectural Management Journal, Vol.7 No 2, pp 141-153

Leyton, R. (1995) Investment appraisal: the key for IT? In Farbey, B., Land, F., F. \& Target, D. (Eds.) Hard Money, Soft Outcomes. Henley on Thames, Alfred Waller Ltd, in association with Unicom.

Lin, C. \& Pervan, G. (2001) "A review of IS/IT investment evaluation and benefits management issues, problems and processes", Information technology evaluation methods \& management. Idea Group Publishing, 22-24.

Mantzana, V. \& Themistocleous, M. (2004) "Identifying and Classifying Benefits of Integrated Healthcare Systems Using an Actor-Oriented Approach", Journal of Computing and Information Technology - CIT, Vol. 12, pp. 265-278.

MaST LIFT Co Website

Merriam-Webster (2005) Merriam-Webster Online Dictionary. Springfield, MA, MerriamWebster.

Mulvany, P. (1999) “Assessing biotechnology impacts" Closing speech, intermediate technology development group associates'day, Intermediate Technology Development Group, Rugby, Warks.

NHS, "No delays: Achieving the 18 week pathway" available at http://www.institute.nhs.uk/no_delays/introduction/no_delays.html (accessed 08 August 2008)

Nogeste, K. (2006) "Development of a method to improve the definition and alignment of intangible project outcomes with tangible project outputs”, RMIT, School of Business

Nogeste, K. \& Walker, D. H. T. (2005) "Project outcomes and outputs: making the intangible tangible”, Measuring Business Excellence, Vol. 9, pp. 55 - 68.

OGC (2003) Managing Successful Programmes, London, The Stationery Office.

OGC (2007) Managing Successful Programmes MSP, London, The Stationery Office.

OGC STDK Home, Delivery Lifecycle: Benefits Management, http://www.ogc.gov.uk/ sdtoolkit/reference/deliverylifecycle/benefits_mgmt.html\#benmanagement1 (accessed 16 August 2008)

Parr, T. \& Williams, D. (2007) Enterprise Programme Management, Palgrave, MacMillan.

Payne, M. (2007) Benefits Management - Releasing project value into the business, Hampshire, UK, Project Manager Today.

Punch, K. F. (2005) Introduction to Social Research: Quantitative and qualitative approaches 2nd edition, Sage.

Reiss, G., A. (2000) A paper for congress www.eprogramme.com/uploads/articles/ (accessed November 2007) 
Reiss, G., Anthony, M., Chapman, J., Leigh, G., Pine, A. \& Rayners, P. (2006) Gower Handbook of programme management, Gower Publishing

Remenyi, D. \& Sherwood-Smith, M. (1998) "Business benefits from information systems through an active benefits realisation programme" International Journal of Project Management, Vol. 16, 81-98.

Sapountzis, S., Harris, K. and Kagioglou, M. (2008a), Benefits Management and Benefits Realisation- A Literature Review, HaCIRIC, the University of Salford, May, Salford, UK

Sapountzis, S., Harris, K. and Kagioglou, M. (2008b), “The need for Benefits Realisation Creating a benefits driven culture in UK's Healthcare Sector”, 1st HaCIRIC Symposium "Redefining healthcare infrastructure Integrating services, technologies and the built environment, 3-4 April 2008, London, UK

Soanes, C. \& Hawker, S. (2005) Compact oxford English dictionary of current English, Oxford, Oxon, Oxford University Press.

Susman, G. I. and Evered R. D. (1978) An assessment of the scientific merits of action Research, Administrative Science Quarterly Vol. 23, pp582 - 603

Thorp, J. (1998) The Information Paradox - realising the business benefits of information technology, Toronto, Canada, McGraw-Hill

Ward, J. Taylor, P. and Bond, P. (1996) "Evaluation and realisation of IS/IT benefits: an empirical study of current practice", European Journal of Information Systems, Vol. 4 pp. 214-25.

Ward, J. \& Daniel, E. (2006) Benefits Management - Delivering Value from IS \& IT Investments, West Sussex UK, Wiley.

Ward, J., Murray, P. \& David, E. (2004) Benefits Management Best Practice Guidelines, Cranfield University, UK

Ward, J., Taylor, P. \& Bond, P. (1996) "Evaluation and realization of IS/IT benefits: an empirical study of current practice”, European Journal of Information Systems, Vol. 4, pp. 214-225.

Ward, J., Taylor, P. \& Bond, P. (1995) "Identification, realisation and measurement of IS/IT benefits: an empirical study of current practice” Brown, A. and Remenyi, D (eds.) Second European Conference on Information Technology Investment Evaluation. Henley Management College, Henley on Thames.Ward, Murray \& David 2004)

Yates, K. Sapountzis, S. Lou, E. and Kagioglou, M. (2008) submitted "BeReal: Tools and methods for implementing benefits realisation and management”, 5th Nordic Conference on Construction Economics and Organisation, 10-12 June 2009, Iceland

Yin, R. (2003) Case Study research: design and methods: Third edition USA: Sage publications. 